\title{
Surface towed electromagnetic system for mapping of subsea Arctic permafrost
}

\author{
Dallas Sherman, Peter Kannberg, and Steven Constable \\ Institute Geophysics and Planetary Physics, University of California, San Diego, La \\ Jolla, California, USA.
}

\begin{abstract}
Sea level has risen globally since the late Pleistocene, resulting in permafrostbearing coastal zones in the Arctic being submerged and subjected to temperature induced degradation. Knowing the extent of permafrost and how it changes over time is important for climate change predictions and for planning engineering activities in the Arctic environment. We developed a controlled source electromagnetic (CSEM) method to obtain information on the depth, thickness, and lateral extent of marine permafrost. To operate in shallow water we used a surface towed electric dipole-dipole CSEM system suitable for deployment from small boats. This system was used to map permafrost on the Arctic shelf offshore Prudhoe Bay, Alaska. Our results show significant lateral variability in the presence of permafrost, with the thickest layers associated with a large river outflow where freshwater influx seems to have a preserving effect on relict subsea permafrost.

Keywords: Controlled source electromagnetics, Permafrost, Arctic hydrology, Gas hydrates
\end{abstract}


1

2

\section{Introduction and Motivation}

Temperatures cold enough to form permafrost have been present in the Arctic since the end of the Pliocene (about 1.9 Ma) and as a result permafrost underlays roughly $20 \%$ of land in the northern hemisphere (Collett et al., 2011). Permafrost is defined as ground that has been held at or below $0^{\circ} \mathrm{C}$ for at least two years, "ice-bearing" specifies that the pore spaces contain a mixture of ice crystals and pore fluid while "ice-bonded" describes cementation of the sediment grains in the permafrost (Osterkamp, 2001). For the remainder of the manuscript we will use "permafrost" to describe a combination of ice-bearing and ice-bonded permafrost.

Over the last 20,000 years sea level has risen $120 \mathrm{~m}$ and submerged portions of Arctic coastline and permafrost. The warm, saline conditions introduced by sea level rise are causing the relict subsea permafrost to thaw (Osterkamp, 2001). The maximum extent of permafrost offshore, therefore, is the $120 \mathrm{~m}$ isobath (Collett et al., 2011), but current seismic studies suggest that permafrost does not extend beyond the $20 \mathrm{~m}$ isobath (Brothers et al., 2012). The reason for discrepancy is uncertain (Collett et al., 2011), and a number of offshore measurements of permafrost with simple and effective ways are required.

Permafrost often has associated gas hydrate, which requires low temperature and high pressures to be stable and typically exists beneath the deep ocean floor. However, consistent cold ground temperature in the presence of ice-bearing permafrost allows gas hydrate to currently exist on land and in shallow water environments. Without the permafrost cap to thermally stabilize them, hydrates could dissociate and release their bound methane 
gas. Methane is a potent greenhouse gas and its release from beneath subsea permafrost would influence current and future warming trends (Ruppel, 2011).

A map of our survey area can be found in Figure 5. Prior studies conducted on the Beaufort Shelf, Alaska, have used the seismic refraction method to infer extent of permafrost. Seismic refraction uses the increase in P-wave velocity $\left(\mathrm{V}_{p}\right)$ due to ice in pore spaces to determine the presence of permafrost. Theory predicts a $\mathrm{V}_{p}$ of $2.5-2.8 \mathrm{kms}^{-1}$ for sands with less than $40 \%$ ice saturation, and above $40 \%$ saturation a sharp jump in seismic velocity to between 3.4 and $4.35 \mathrm{kms}^{-1}$ due to the onset of cementation of sediment grains (Johansen et al., 2003). In the Beaufort Sea velocities varied between 1.7 - $4.6 \mathrm{kms}^{-1}$ with all permafrost layer refractions (PLRs), defined as $\mathrm{V}_{p}>2.3 \mathrm{kms}^{-1}$, occurring within $30 \mathrm{~km}$ of the coast and shallower than $20 \mathrm{~m}$ water depth (Brothers et al., 2012).

Although PLRs can be used to define the lateral extent of permafrost, the seismic method has difficulty determining depth boundaries and bulk properties of permafrost (Brothers et al., 2012). The velocity contrast at the top boundary is so large that most of the seismic energy does not propagate beneath it. The bottom permafrost boundary is likely diffuse and is a velocity decrease, both of which result in a weak or non-existent refraction signal. As a consequence, the seismic method can image the top of the permafrost layer at best. Additionally, the refraction method cannot differentiate between frozen and unfrozen fine grained sediments, which means the depth obtained from this method may not be the top of the permafrost layer if fine sediments overly coarse ones (Brothers et al., 2012). 
Electromagnetic methods complement seismic data by resolving the top and bottom boundaries, as well as estimating the volume fraction of permafrost (e.g., Hauck, 2016; Todd and Dallimore, 1998). CSEM is sensitive to the resistivity increase caused by ice forming in pore spaces, as well as to the resistivity decrease below the permafrost as the sediments transition to an unfrozen state. Onshore boreholes have measured ice-bonded permafrost with resistivities from $100 \Omega \mathrm{m}$ to over $1000 \Omega \mathrm{m}$ to depths of $660 \mathrm{~m}$ near the coast of Prudhoe Bay (Collett et al., 1989; Jorgenson et al., 2008). Below the permafrost layer resistivities drop to between 5 and $15 \Omega \mathrm{m}$ (Collett et al., 1989). We expect the resistivity of offshore ice-bearing permafrost to be lower than the measured onshore values because of intrusive saline pore fluids (Daniels et al., 1976). Land borehole measurements of hydrate beneath permafrost in the Eileen accumulation, located near the coastline just west of Prudhoe Bay, reach $2000 \Omega \mathrm{m}$ at a depth of about $600 \mathrm{~m}$ (Collett et al., 2011). Gas hydrate occurs at greater depths and has a higher resistivity than permafrost, and so with careful interpretation one might be able to distinguish between the two.

\section{Methodology}

Shallow seafloor resistivity, a good proxy of marine geological settings, is effectively mapped using a fixed-offset towed array (e.g., Constable et al., 2016). Towed systems have been used extensively in deep water and are faster to use than deploying seafloor CSEM receivers. However, shallow water depths on the Arctic shelf make using a deep-towed system unfeasible and make a surface towed system more appropriate. 


\subsection{Instrument Design}

We had previously developed a deep-towed fixed-offset CSEM system to map gas hydrates, the "Vulcan" system of Constable et al. (2016). This design was adapted for a surface-towed system by repackaging our Vulcan deeptow receivers in buoyant PVC cases. We call the assembly a "Porpoise" since they occasionally appear to leap from the water when encountering ice. The data logger within the plastic case records inline electric field, acceleration in three directions, and a timing pulse sent from an external GPS receiver. Inline electric field is measured using a $2 \mathrm{~m}$ dipole held $0.67 \mathrm{~m}$ underwater. As with the Vulcan instruments, we chose rigid antennas instead of cable arrays to avoid motional noise associated with cable motion through Earth's magnetic field (Constable et al., 2016). The Vulcan system is equipped with the ability to receive real-time data and telemetry from the receivers. These features are necessary for maintaining a steady receiver depth, and to prevent unwanted contact with the seafloor, as well as monitoring data quality during tows lasting many days. Neither of these concerns affect Porpoises because their positions can be verified by sight and they are typically only towed for hours at a time, allowing for frequent data quality checks without the real-time capabilities. A schematic of the Porpoise system is shown in Figure 1 and pictures of the instrument can be found in Figure 2.

GPS receivers are attached to the top of the Porpoises on short masts and a serial data logger within the logger package records time and location. A second serial data logger records pitch, roll, and heading from a compass/tiltmeter every second. Conductivity, temperature, and depth (CTD) were continuously measured in the top meter of sea water by towing a CTD 

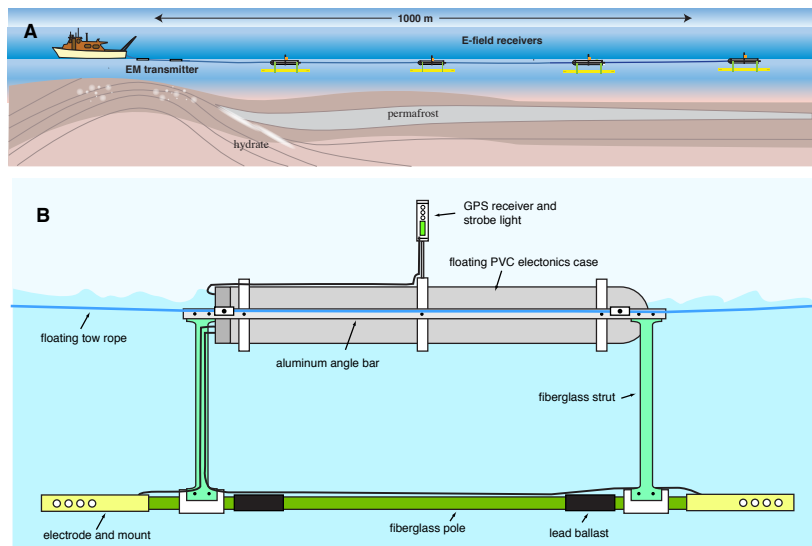

C

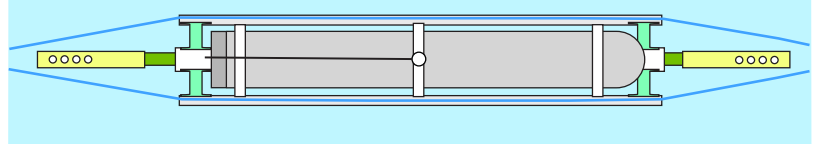

Figure 1: A: Surface-towed Porpoise array. Multiple receivers are easily clipped into the tow rope during deployment. B: Side view schematic of a Porpoise receiver. C: Plan view of a Porpoise receiver.

package alongside the vessel. When towing into deeper water, the CTD system was lowered to the bottom once the vessel was stopped and the Porpoises were on deck to measure a conductivity profile. A total of twelve conductivity profiles were collected and reached a maximum depth of $10 \mathrm{~m}$.

The transmitter operates off 110 - 240 VAC power and can output up to $50 \mathrm{~A}$ on a $50 \mathrm{~m}$ antenna in the form of an arbitrary GPS stabilized ternary waveform. Data were collected over two years, in the first year a $50 \mathrm{~m}$ antenna was used with between 30 and 40 amps output. In the second year, the transmitter was upgraded to produce a current controlled output of 40 amps on a $45 \mathrm{~m}$ antenna. 


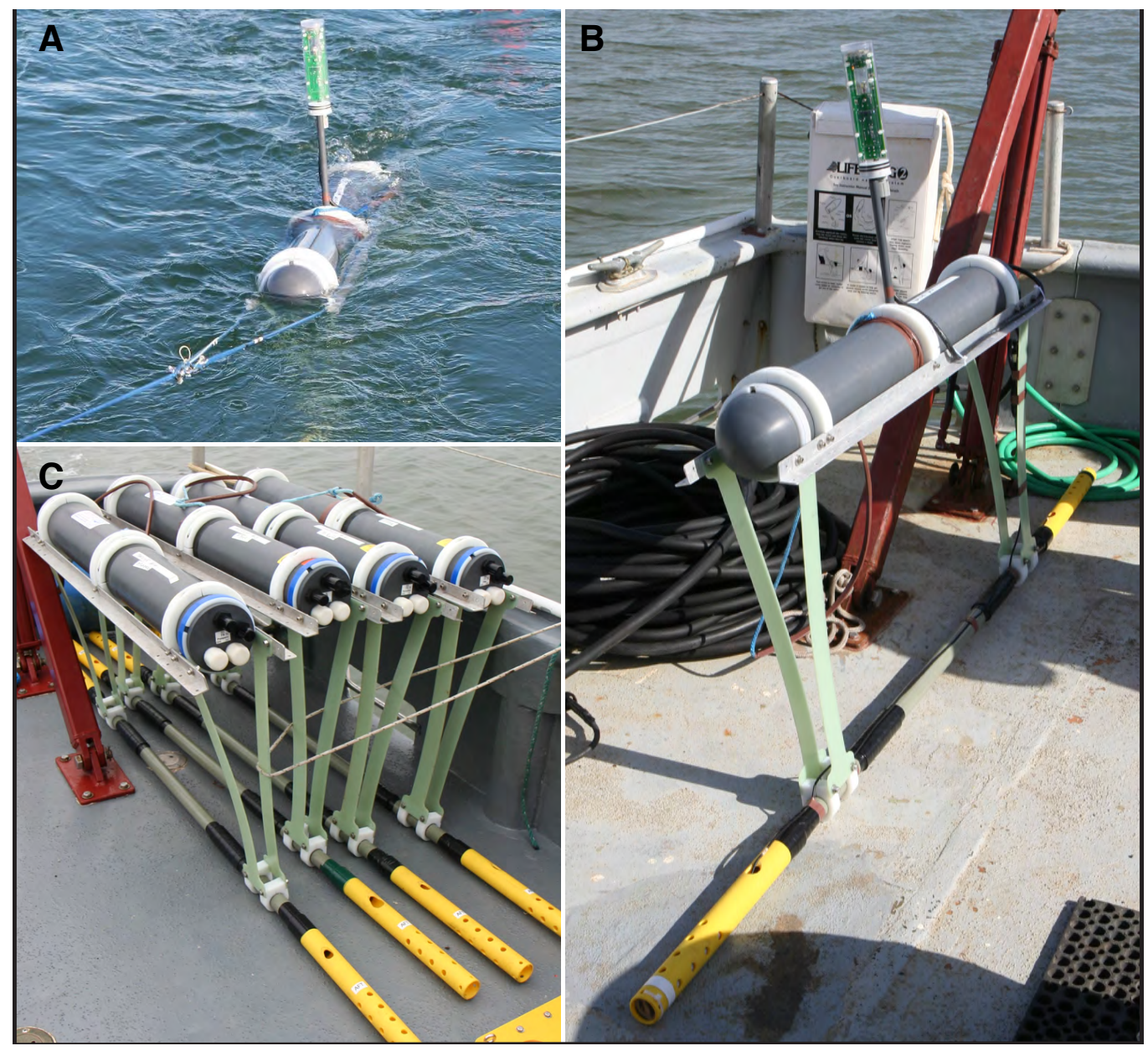

Figure 2: A: Porpoise floating on the surface after being deployed. B: Porpoise ready to be deployed. C: All four Porpoises stored on deck, electrodes and GPS receivers still need to be attached. 
The entire Porpoise system is light and small enough to be easily air freighted, transported in one load using a utility vehicle, and operated off a small $(16 \mathrm{~m})$ fishing boat. This makes it a relatively easy and inexpensive system to operate, and while designed to operate in the shallow Arctic shelf, it has already been used for a number of other applications including groundwater and geothermal exploration in the Atlantic and Gulf of California, respectively (e.g., Martin, 2015).

Shown in Figure 3 are noise spectra of Porpoises at three offsets compared with published noise spectra of a Vulcan deep-tow instrument and an ocean bottom electromagnetic (OBEM) receiver (Constable et al., 2016). At $1 \mathrm{~Hz}$ noise levels are on the order of a few microvolts and at $30 \mathrm{~Hz}$ the noise contributes tens of nanovolts. The peak centered around $0.3 \mathrm{~Hz}$ is due to wave noise or strumming of the instrument. Porpoise receiver noise is higher than that of the Vulcan because of increased wave and environmental noise on the surface. The noise floor of the OBEM is the lowest because it is subject to fewer motional noise sources.

\subsection{Sensitivity to target}

We conducted synthetic forward modeling to determine the offsets and frequencies most sensitive to permafrost, modeled as a $200 \mathrm{~m}$ thick layer of $100 \Omega \mathrm{m}$ material buried at a depth of $200 \mathrm{~m}$ in $1 \Omega \mathrm{m}$ marine sediment. This model was intentionally chosen to be conservative and was constructed based on modelling and well log data (Osterkamp, 2001). Forward responses were calculated for the permafrost model as well as a halfspace of pure sediment. In both cases water depth was $5 \mathrm{~m}$ and the calculation was done for offsets of 100 to $1100 \mathrm{~m}$ and frequencies of 1 to $40 \mathrm{~Hz}$. Figure 4 shows (A) the 


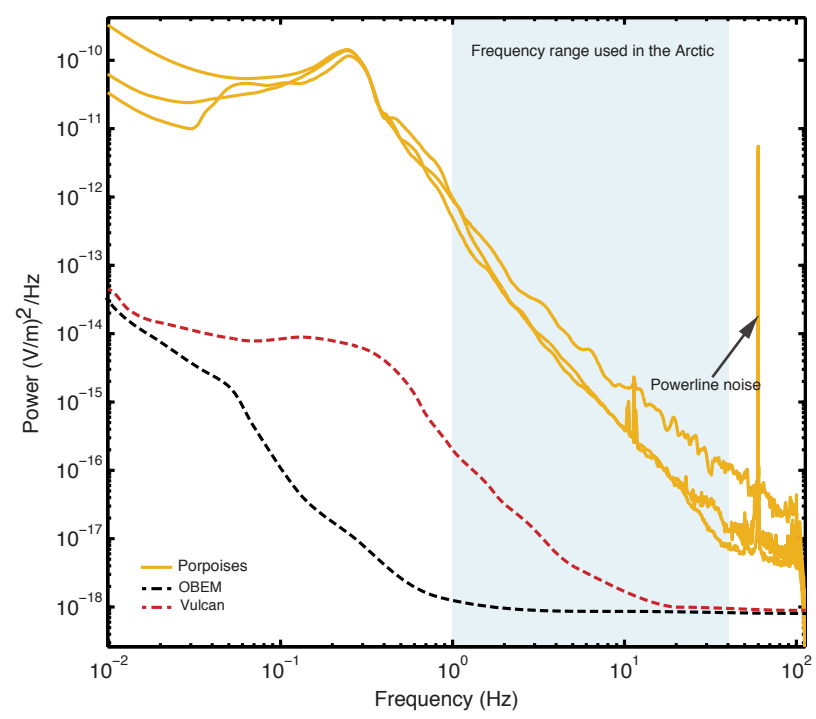

Figure 3: Power spectra of various EM receivers. Porpoise data were collected on a test cruise offshore San Diego in May of 2014. Vulcan and OBEM spectra are from Constable et al. (2016) and are shown as broken lines. 
amplitude of the permafrost model response normalized by the halfspace response and (B) the difference in model phases. Largest sensitivity to a permafrost layer occurs at offsets longer than $500 \mathrm{~m}$ and at frequencies less than $30 \mathrm{~Hz}$.

In our survey design Porpoises were towed at offsets of 250, 500, 750 and $1000 \mathrm{~m}$. We find that including a shorter range Porpoise helps constrain the shallow sediment and ultimately helps resolve permafrost in inversions of the data. The array was kept at $1 \mathrm{~km}$ in length for logistical reasons, but we experimented with moored seafloor receivers that measured two orthogonal directions of the horizontal electric field. Moored receivers were weighted and marked with a buoy so that they could be deployed and recovered by hand. Source receiver offsets of up to $6 \mathrm{~km}$ were obtained using these receivers. We transmitted a $1 \mathrm{~Hz}$ fundamental of Waveform- $\mathrm{D}$, a modified square wave that spreads power from the fundamental frequency into higher odd harmonics spanning at least one decade (Myer et al., 2010).

\section{Survey Area}

The surface towed Porpoise system was used in the summers of 2014 and 2015 on the Beaufort Shelf off the north coast of Alaska, with operations based out of Prudhoe Bay on the North Slope. The Beaufort shelf is 80 - $100 \mathrm{~km}$ wide with water depths less than $20 \mathrm{~m}$ to more than $20 \mathrm{~km}$ offshore. The shelf was not glaciated during the late Pleistocene, rather was exposed to subfreezing temperatures and formed permafrost hundreds of meters thick. Holocene sediments are missing over much of the Beaufort shelf because of the recent (7.5ky) $40 \mathrm{~m}$ sea level rise (Hill et al., 1985). Instead, 


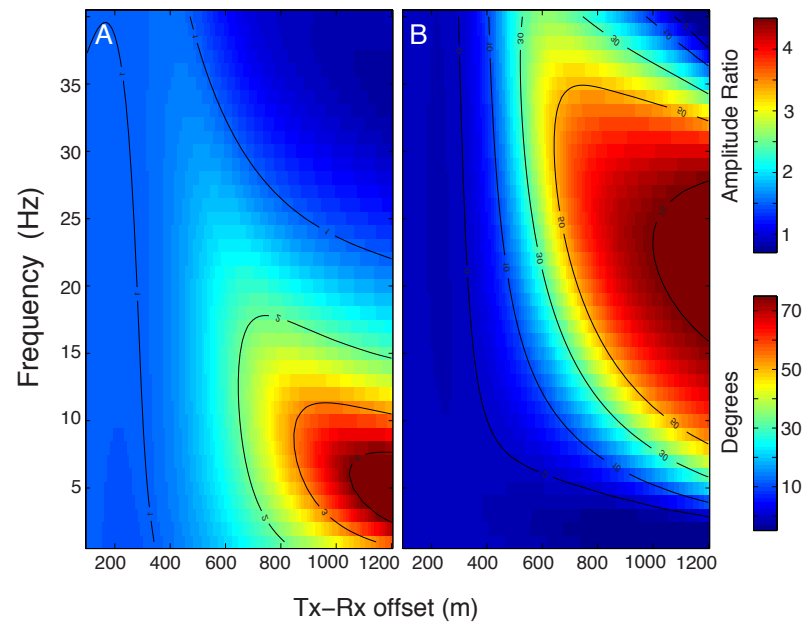

Figure 4: A: Amplitude anomaly or permafrost model amplitude normalized by a $1 \Omega \mathrm{m}$ halfspace amplitude. An amplitude anomaly of 1 indicates no difference. B: Phase anomaly or phase difference between the two models. The permafrost model was a $200 \mathrm{~m}$ thick permafrost layer with $100 \Omega \mathrm{m}$ resistivity buried at a depth of $200 \mathrm{~m}$ in $1 \Omega \mathrm{m}$ sediments.

Tertiary and Quaternary sand, silt, and clay make up the bulk of shallow shelf sediments (Houseknecht and Bird, 2011). Sedimentary rocks in this region can be divided into 4 sequences: the Franklinian (Cambrian to Devonian), Ellesmerian (Mississippian to Jurassic), Beaufortian (Jurassic-Lower Cretaceous), and Brookian (Cretaceous-Holocene) (Hubbard et al., 1987). All known and inferred gas hydrate on North Slope is found in the Brookian sequence (Collett et al., 2011).

Our surveys were conducted off the R/V Ukpik during late July/early August in 2014 and 2015, shortly after the ice pack broke away from shore. In total we towed 12 days and covered $365 \mathrm{~km}$, on average $30 \mathrm{~km}$ per 12-hour day (compare this to $3 \mathrm{~km}$ per 12-hour day when using deployed receivers (e.g., Weitemeyer et al., 2006)). Initially the plan was to tow shore perpendicular 


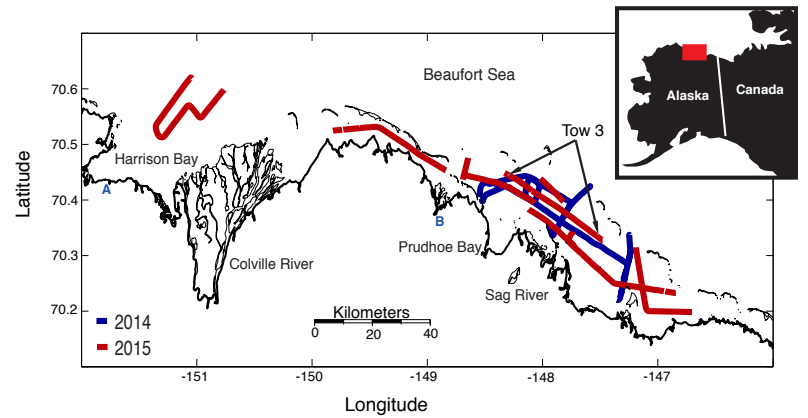

Figure 5: Ship tracks from both years of data collection. A: borehole near Harrison Bay. B: borehole near Prudhoe Bay. Both years the edge of the ice pack was near the barrier islands. An inversion of Tow 3 is shown in Figure 8.

lines coincident with seismic data collected by the U.S. Geological Survey. However, the annual sea ice pack limited how far offshore we were able to collect data and so instead we focused our efforts on expanding coverage along the shoreline. In 2014 the edge of the sea ice was near the $20 \mathrm{~m}$ isobath, where seismic data indicates the edge of the permafrost lies. Although in 2015 we returned later in the season in hopes of collecting data farther offshore, the sea ice was in fact closer to shore and prevented us from towing past the seismically determined edge of permafrost. Harrison Bay was the one location where we successfully collected data across the presumed edge of permafrost. Tow lines for both years are shown in Figure 5.

\section{Results and Discussion}

The inline electric field time series measured on each Porpoise was Fourier transformed and stacked into 60 second windows (Myer et al., 2010). Stacking the data increases its statistical reliability and provides estimates of er- 


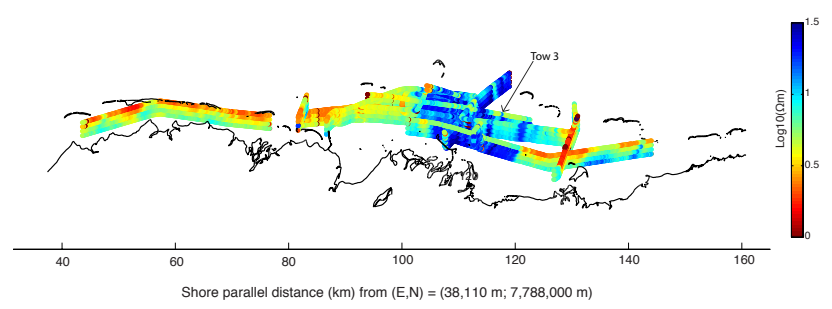

Figure 6: Fence diagram of offset apparent-resistivity pseudosections offshore Prudhoe Bay and the Sagavanirktok (Sag) river outflow for both years computed for $3 \mathrm{~Hz}$ amplitudes. Blue corresponds to higher resistivity values (up to $30 \Omega \mathrm{m}$ ) while red is more conductive (down to $1 \Omega \mathrm{m}$ ).

rors. Processing was done for eleven harmonics of Waveform-D, from the $1 \mathrm{~Hz}$ fundamental to $33 \mathrm{~Hz}$. We created pseudosections by calculating the forward solution for 1D models, including appropriate water depth from an echosounder and seawater conductivity from CTD measurements, underlain by halfspaces ranging from 0.1 to $1000 \Omega \mathrm{m}$ and interpolating to find the best resistivity for each value of stacked amplitude. Appropriate skin depths at each frequency can be used to create a frequency pseudosection at one source-receiver offset (e.g., Weitemeyer and Constable, 2010), but with four different offsets we can create the more conventional offset pseudosection for each frequency (Hallof, 1964). Pseudosections are useful for displaying the lateral variability of a data set, but have limited ability to determine depths (Weitemeyer et al., 2006). The pseudosections for a frequency of $3 \mathrm{~Hz}$ are shown in Figures 6 and 7, short offsets are plotted as shallow structure and long offsets as deeper structure.

The offset pseudosections (Figures 6 and 7 ) show significant lateral variability in permafrost extent. Harrison Bay appears very conductive with 


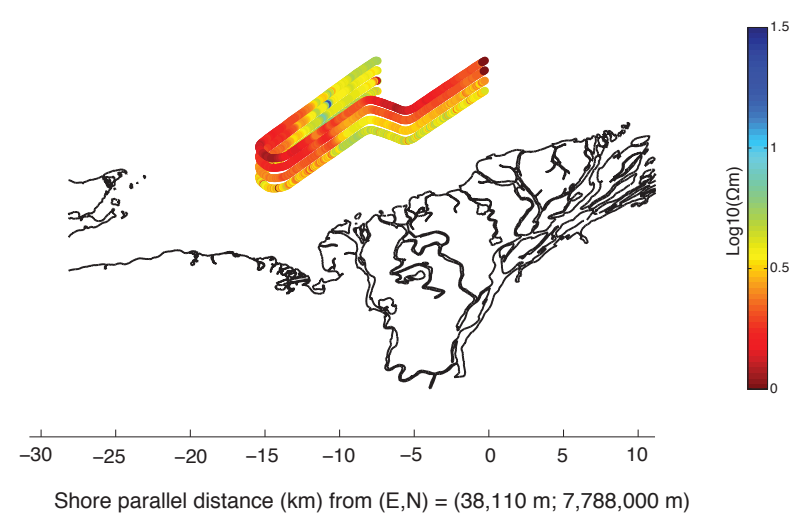

Figure 7: Fence diagram of offset apparent-resistivity pseudosection in Harrison Bay and near the Colville river outflow computed for $3 \mathrm{~Hz}$ amplitudes.

highest resistivities near $10 \Omega \mathrm{m}$, which is unexpected given that permafrost is seismically inferred in this area (Brothers et al., 2012). However, it is consistent with well logs that show thinning of the ice bearing permafrost layer onshore to the west of Prudhoe Bay (Collett et al., 1989). Onshore at Harrison Bay a well log (labelled A in Figure 5) measures maximum resistivity near $100 \Omega \mathrm{m}$ down to $120 \mathrm{~m}$, where resistivity drops to over $10 \Omega \mathrm{m}$ and the base of the ice-bearing layer is seen at $300 \mathrm{~m}$ (Collett et al., 1989). If most of the $120 \mathrm{~m}$ thick resistive layer has thawed, the underlying permafrost would be consistent with resistivity values in the pseudosection. Along the coast between Harrison Bay and Prudhoe Bay there is a clear layer of conductive sediments overlying a buried layer of more resistive material, interpreted as permafrost. Just east of Prudhoe Bay there is an increase in resistivity at all depths, implying that permafrost is pervasive in the area near the Sagavanirktok (also called the Sag) river outflow. Because of freshwater influx from rivers and melting of sea ice, sea water conductivity was variable across 
the entire survey area. In the top meter ocean conductivity ranged from 0.3 to $0.5 \Omega \mathrm{m}$, but at depth remained more constant near $0.4 \Omega \mathrm{m}$. Seawater conductivity variations and water depth were included in the 1D model layers used for pseudosections and therefore do not cause the apparent resistivity variations.

Inversions were done using the MARE2DEM adaptive refinement finite element code (Key, 2016). Two dimensional (2D) inversion of CSEM data is computationally expensive, and many inversions must be carried out to fully understand error structure and the trade off between misfit and model complexity (e.g., Constable et al., 2015). We present one preliminary inversion in Figure 8 to illustrate the difference between pseudosections and actual inversion. The inversion shown is for Tow 3 , indicated in the map of the survey area in Figure 5, and is limited to amplitude, the three largest harmonics of Waveform-D (3, 7, and $13 \mathrm{~Hz})$ for the first three Porpoises (offsets of 250, 500 , and $750 \mathrm{~m}$ ) and the largest two harmonics $(3$ and $7 \mathrm{~Hz}$ ) for the last $1000 \mathrm{~m}$ offset Porpoise. The inversion grid size ranged from quadrilaterals $150 \mathrm{~m}$ wide by $10 \mathrm{~m}$ deep in the shallowest region up to $250 \mathrm{~m}$ by $50 \mathrm{~m}$ at greater depths. The increasing grid size is meant to mimic the loss of spatial resolution with depth as well as decrease computational resources. The inversion results are shown in Figure 9 as a contour plot with contours at 3, 20 , and $100 \Omega \mathrm{m}$ to better differentiate the likely ice-bonded permafrost layer. Due to the variation in water conductivity across this region, we allowed a 2-layer ocean model be free parameters in the inversion, bounded by the maximum and minimum values that were measured with our towed CTD. The inversion chose $0.5 \Omega \mathrm{m}$ for the top layer and $0.45 \Omega \mathrm{m}$ for the bottom, 


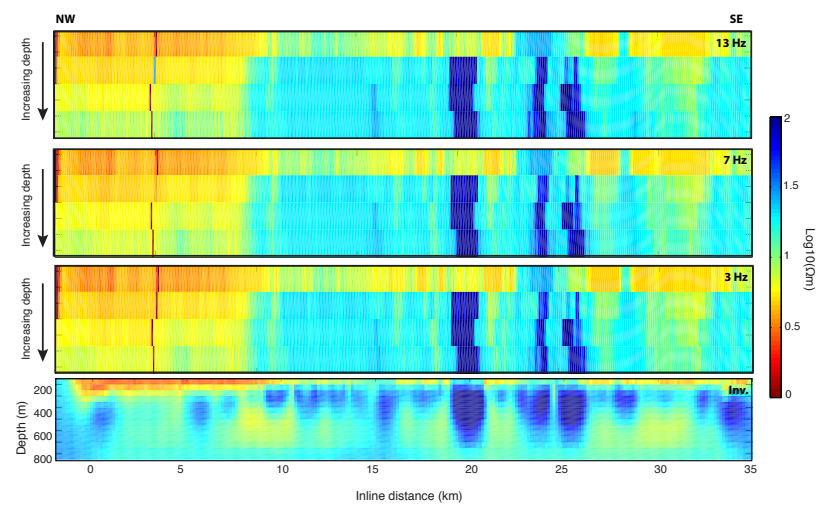

Figure 8: Inversion of Tow 3, a line spanning the Sag River outflow (bottom). The river outflow begins about $8 \mathrm{~km}$ inline distance. Psuedosections for 3,7 and $13 \mathrm{~Hz}$, the three inversion frequencies, are plotted above in order of increasing depth penetration. Note that data contributing to the conductive artifact present in the pseudosections near $3 \mathrm{~km}$ inline distance have been removed in the inversion. The inversion fits to an RMS of 1.5 with an error floor of $3 \%$.

which are consistent with the upper range of the CTD measurements.

On the northwestern end of Tow 3, in the section before the Sag River outflow, we see conductive sediments overlying two resistive patches. The southeastern side of the inversion shows a thin layer of conductive marine sediments at the surface, underlain by a non-uniform layer of resistive material. Below the resistive layer the inversion returns to higher conductivities consistent with freshwater sediments. The peak resistivity in the tow 3 inversion is over $300 \Omega \mathrm{m}$, which we consider consistent with ice-bonded permafrost. The pseudosections for the 3 inverted frequencies of Tow 3 are plotted above the inversion result, and results are consistent with the inversion. The inversion fits the data to an RMS of 1.3 with a $3 \%$ noise floor and a comparison of data and model amplitudes is shown in Figure 10. 


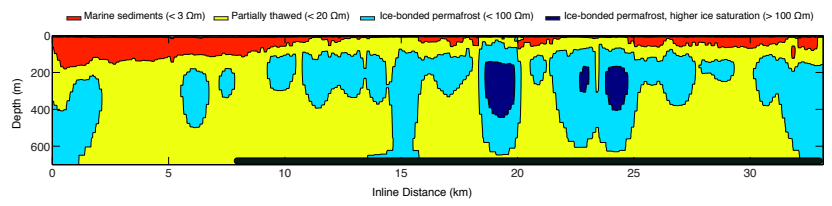

Figure 9: Same inversion of Tow 3 shown in Figure 8, but plotted with four major contours colored with the same colorscale as Figure 8. The first regime is for marine sediments with resistivities $<3 \Omega \mathrm{m}$, followed by resistivities $<10 \Omega \mathrm{m}$ which could be partially thawed icebearing permafrost or freshwater pore fluids, and the threshold for ice-bonded permafrost was set at $>20 \Omega \mathrm{m}$ (Collett et al., 1989) with over $100 \Omega \mathrm{m}$ indicating regions of exceptionally high ice saturation. The dark bar at the bottom of the figure indicates the region of the Sag River outflow.

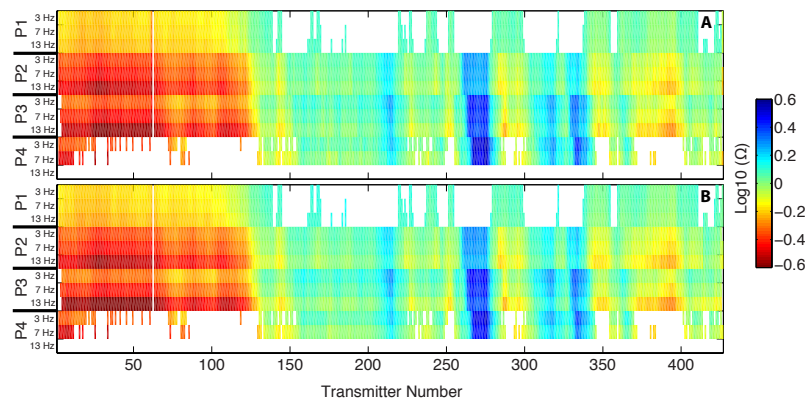

Figure 10: A: Amplitude at each frequency and offset for data inverted in Figure 8, normalized by the median amplitude of each offset. B: Inverted amplitude for each frequency and offset, normalized by the same values as the data amplitudes. Gaps show data that has been filtered out due to poor signal to noise ratio or from amplifier clipping. 
Because CSEM and seismic refraction methods are sensitive to different physical phenomena, we do not expect them to yield identical information, and indeed if they did it would be redundant to conduct both surveys. Strong seismic refractions occur when there is a sharp velocity increase while the CSEM method is more sensitive to the total ice fraction. In the region of the Sag River outflow, a seismic refraction survey (Brothers et al., 2012) measured an increased p-wave velocity $\left(V_{p}>2.8 \mathrm{~km} / \mathrm{s}\right)$ where the CSEM pseudosections show resistive anomalies over $30 \Omega \mathrm{m}$. Together, these observations indicate an extensive amount of permafrost correlated with the river outflow. Seismic refraction data continues to see elevated p-wave velocities $\left(\mathrm{V}_{p}>2.8 \mathrm{~km} / \mathrm{s}\right)$ from northwest of the Sag River through Harrison Bay, while the resistivity values decrease. Resistivity still provides a positive indication of permafrost, but lower resistivity implies that there is less total ice volume, and is again in agreement with the thinning trend from Prudhoe Bay to Harrison Bay seen in onshore permafrost. The pseudosections would not resolve a thin layer of ice-bonded permafrost and are likely producing an average resistivity of ice-bonded permafrost and surrounding marine sediments.

In contrast, to the immediate southeast of the Sag River, seismic refraction data detected lower velocity increases $\left(V_{p}>2.3 \mathrm{~km} / \mathrm{s}\right)$ consistent with ice-bearing, but not ice-bonded permafrost. CSEM pseudosections show continued elevated resistivity $(>10 \Omega \mathrm{m})$ before transitioning to higher conductivities at short offsets (shallow) and resistivities of 8-10 $\Omega \mathrm{m}$ at long offsets (deeper). Either the ice-bearing permafrost has a stronger resistivity signature than velocity increase or the resistivity anomaly in this area is from a different source, i.e. freshening of porewater fluids. Ice-bonded permafrost 
is impermeable to water, so any ground water needs to flow under or around the ice-bonded permafrost. The southeast side of the Sag River is the side without ice-bonded permafrost (Brothers et al., 2012) and therefore where fresh groundwater can flow and freshen the pore fluid. Beneath the permafrost layer should be water saturated sediment, offshore this may be brine or fresh, but onshore it will likely be fresh. Borehole measurements taken beneath the permafrost layer onshore show resistivities up to $20 \Omega \mathrm{m}$ (Collett et al., 2011), which implies that freshening of pore fluids offshore cannot increase resistivity beyond about $20 \Omega \mathrm{m}$. Therefore, we infer that the very high resistivity values offshore Sag River are from increased ice content. Fresh ground water flowing beneath this permafrost layer, however, may affect our ability to detect the base of permafrost in this area.

Modeling suggests that groundwater flow preserves permafrost by freshening the porewater fluid and raising the freezing temperature above the ambient ocean temperature (Frederick and Buffet, 2015). By definition, permafrost is ground that is below the freezing piont of water. Therefore, when groundwater is flowing into areas where permafrost exists it is flowing into a temperature regime where it will freeze, turning to ice and preserving the thickness of the permafrost layer. Using a synthetic model of the continental shelf, Frederick and Buffet [2015] calculated the offshore extent of subsea permafrost in the presence of a ground water flow which ranged from 0 to over $140 \mathrm{~m}^{3} \mathrm{yr}^{-1} \mathrm{~m}^{-1}$ over many glacial cycles. They concluded that local hydrology is as important as paleoclimate conditions and sea level rise in determining current permafrost extent. While this model is consistent with the presence of permafrost offshore the Sag River, the same results are not 
seen offshore the Colville River. Brothers et al. (2012) also note that larger rivers can act as a heat source and prevent permafrost from forming when exposed to sub-freezing temperatures (Frederick and Buffet, 2014). Taliks, or unfrozen regions in otherwise continuous permafrost, occur in paleo river channels, such as the Colville River which has a talik extending hundreds of feet beneath its bed (Williams, 1970). The Colville is larger than the Sag and may be an example of the latter effect of local hydrology and be acting as a heat source rather than a preserving force.

\section{Conclusions}

Our surface towed CSEM system was successful at characterizing resistivity to a depth of about $800 \mathrm{~m}$ in $0-8 \mathrm{~m}$ water depths offshore Prudhoe Bay. Apparent resistivity in the region ranged from $1 \Omega \mathrm{m}$, a value typical of marine sediments, to over $100 \Omega \mathrm{m}$, which we interpret as ice-bonded permafrost. In areas with seismically interpreted permafrost, apparent resistivity varied from $10 \Omega \mathrm{m}$ to over $100 \Omega \mathrm{m}$, indicating that there is both ice-bearing and ice-bonded permafrost offshore Prudhoe Bay and that EM methods may be capable of distinguishing between the two. Inverted base of offshore permafrost is near $600 \mathrm{~m}$, consistent with well logs measuring an onshore permafrost layer of $660 \mathrm{~m}$ at Prudhoe Bay. Pseudosections and initial inversions both show increased resistivity at the Sag River outflow, offering support to the idea that groundwater preserves permafrost. Future work will include carrying out inversions on all lines, integrating seismic horizons into the inversions, and further exploring the role of local hydrology in permafrost preservation. 


\section{Acknowledgements}

Funding was provided by Department of Energy (contract no. DE-FE0010144). Special thanks go to Carolyn Ruppel of the USGS for extensive advice on logistics and providing seismic line locations. We thank the Scripps Marine EM Laboratory engineers, Jacques Lemire and John Souders, for their work on the design of the Porpoise system. We thank Kerry Key for use of his MARE2DEM inversion code, which can be downloaded from http://mare2dem.ucsd.edu. We are grateful for the comments and suggestions from two annonymous reveiwers that helped improve the manuscript. BP provided access to West Dock. We thank the owner and captain of the RV Ukpik, Bill Kopplin and Mike Flemming. Finally, we acknowledge the Scripps Electromagnetic Methods Consortium for continued support and funding of DS. Data used in this paper may be found online at http://marineemlab.ucsd.edu.

Brothers, L. L., P. E. Hart, and C. D. Ruppel (2012), Minimum distribution of subsea ice-bearing permafrost on the U.S. Beaufort Sea continental shelf, Geophys. Res. Lett., 39, L15501.

Collet, T. S., L.W. Myung, W. F. Agena, J. J. Miller, M. V. Lewis, R. Boswell, T. L. Inks (2011) Permafrost-associated natural gas hydrate occurrences on the Alaskan North Slope, Mar. Pet. Geol., 28, 279-294

Collett, T.S., K.J. Bird, K.A. Kvenvolden, and L.B. Magoon (1989), Map showing the depth to the base of the deepest ice-bearing permafrost as determined from well logs, North Slope, Alaska: USGS Oil and Gas Investigations Map 222. 
Constable, S. C., A. Orange, and K. W. Key (2015) And the geophysicist replied: "Which model do you want?", Geophysics, 80 (3) 197-212

Constable, S. C., P. Kannberg, K. A. Weitemeyer (2016) Vulcan: A deeptowed CSEM receiver, Geochem. Geophy. Geosy., 17, 1042-1064

Daniels, J.J., G.V. Keller, and J.J. Jacobson (1976) Computer-assisted interpretation of electromagnetic soundings over a permafrost section. Geophysics. 41(4) 752-765

Frederick, J. M., and B. A. Buffett (2015), Effects of submarine groundwater discharge on the present-day extent of relict submarine permafrost and gas hydrate stability on the Beaufort Sea continental shelf. J. Geophys. Res. Earth Surf., 120, 417432

Frederick, J. M., and B. A. Buffett (2014), Taliks in relict submarine permafrost and methane hydrate deposits: Pathways for gas escape under present and future conditions, J. Geophys. Res. Earth Surf., 119, $106-122$

Hallof, P. G. (1964) A comparison of the various parameters employed in the variable-frequency induced-polarization method. Geophysics. 29(3) 425433

Hauck, C. (2016) Frozen ground monitoring using DC resistivity tomography. Geophys. Res. Lett.. 29(21)

Hill, P.R., P.J. Mudie, K. Moran and S.M. Blasco (1985) A sea-level curve for the Canadian Beaufort Shelf, Can. J. Earth Sci., 22(1) 1383-1393 
Houseknecht, W., and K. J. Bird (2011) Geology and petroleum potential of the rifted margins of the Canada Basin, in Arctic Petroleum Geology, Geol. Soc. Mem., vol. 35, edited by A.M. Spencer et al., 509-526, Geol. Soc., London

Hubbard, R. J., S. P. Edrich, and R. P. Rattey (1987) Geologic evolution and hydrocarbon habitat of the 'Arctic Alaska Microplate'. Mar. Pet. Geol., 4(1) $2-34$

Johansen, T. A., P. Digranes, M. van Schaack, and I. Lonne (2003), Seismic mapping and modeling of near-surface sediments in polar areas, Geophysics, 62(2), 1-8

Jorgenson, T., K. Yoshikawa, M. Kanevskiy, Y. Shur, V. Romanovsky, S. Marchenko, G. Grosse, J. Brown, and B. Jones (2008), Permafrost characteristics of Alaska, Institute of Northern Engineering, University of Alaska Fairbanks, 1 p.

Key, K. W. (2016). MARE2DEM: a 2-D inversion code for controlled-source electromagnetic data. Geophys. J. Int., 207, 571-588

Martin, T. P. (2015). Mapping Porosity Structure Offshore Torrey Pines State Natural Reserve and Del Mar, California Using a Surface Towed EM System. UC San Diego: b8887341. Retrieved from: http://escholarship.org/uc/item/45p0062c. Accessed on May 2, 2016.

Myer, D., S. C. Constable, K. W. Key (2010), Broad-band waveforms and robust processing for marine CSEM surveys. Geophys. J. Int., 184, 689698. 
Osterkamp, T. E., (2001) Sub-sea permafrost in Encyclopedia of Ocean Sciences (Second Edition), pp 559-569, Academic Press.

Ruppel, C.D. (2011) Methane Hydrates and Contemporary Climate Change. Nature Education Knowledge, 3(10):29

Todd, B. J., S. R. Dallimore (1998) Electromagnetic and geological transect across permafrost terrain, Mackensie River delta, Canada. Geophysics, 63(6), 1914-1924

Weitemeyer, K. A., and S. C. Constable (2010) Mapping shallow geology and gas hydrate with marine CSEM surveys. First Break, 28, 97-102.

Weitemeyer, K. A., S. Constable, K. W. Key, J. P. Behrens, (2006) First results from a marine controlled-source electromagnetic survey to detect gas hydrates offshore Oregon, Geophys. Res. Lett., 33, L03304

J. R. Williams (1970) Ground Water in the Permafrost Regions of Alaska. Geological Survey Professional Paper 696 